\title{
Communication between Hin recombinase and Fis regulatory subunits cluring coordinate activation of Hin-catalyzed site-specific DNA inversion
}

\author{
Stacy K. Mericke, ${ }^{1}$ Michad J. Haykinson, ${ }^{1}$ and Reid C. Johnson ${ }^{1,2}$ \\ ${ }^{1}$ Department of Biological Chemistry, School of Medicine, University of California at Los Angeles, Los Angeles, California \\ 90095-1737 USA; ${ }^{2}$ M olecular Biology Institute, University of California at Los Angeles, Los Angeles, California 90095 USA
}

The Hin DNA invertase becomes catalytically activated when assembled in an invertasome complex containing two Fis dimers bound to an enhancer segment. The region of Fis responsible for transactivation of Hin contains a mobile $\beta$-hairpin arm that extends from each dimer subunit. We show here that whereas both Fis dimers must be capable of activating $\mathrm{Hin}$, Fis heterodimers that have only one functional activating $\beta$-arm are sufficient to form catalytically competent invertasomes. Analysis of homodimer and heterodimer mixes of different Hin mutants suggests that Fis must activate each subunit of the two Hin dimers that participate in catalysis. These experiments also indicate that all four Hin subunits must be coordinately activated prior to initiation of the first chemical step of the reaction and that the process of activation is independent of the catalytic steps of recombination. We propose a molecular model for the invertasome structure that is consistent with current information on protein-DNA structures and the topology of the DNA strands within the recombination complex. In this model, a single Fis activation am could contact amino acids from both Hin subunits at the dimer interface to induce a conformational change that coordinately positions the active sites close to the scissile phosphodiester bonds.

[Key Words: Site-specific DNA recombination; DNA invertase; Fis; enhancer; invertasome]

Received June 5, 1998; revised version accepted July 20, 1998.

Precise control of specialized recombination is necessary because of the potentially severe consequences of aberrant chromosome rearrangements. In the Hin-catalyzed site-specific DNA inversion reaction, the Fis regulatory protein bound to a remote enhancer segment controls the di rectionality and rate of the reaction (Johnson 1991; van de Putte and Goosen 1992). Fis activates the Hin recombinase only when the protein-bound enhancer and two specific recombination sites have assembled into a topol ogically correct structure for generating inversion. $M$ any types of nucleic acid transactions, including transcription, replication, and RNA splicing, are regulated from distant sites. The relative simplicity of the Hin recombination reaction combined with the current structural knowledge about the participating proteins make it an attractive system for deciphering the biochemical mechanisms involved in the regulation of enzymatic activity from a remote enhancer.

${ }^{2}$ Corresponding author.

E-MAIL rcjohnson@mednet.ucla.edu; FAX (310) 206-5272.
Hin is one of a number of homologous DN A invertases that mediate the alternate expression of different bacterial or viral genes in various contexts (Glasgow et al. 1989b). The Hin-catalyzed DNA inversion reaction enables Salmonella sp. to escape a primary immune response by switching the orientation of a promoter located near one end of a 1-kb segment of the chromosome. In one orientation, this promoter transcribes one of the two fl agel lin genes, whose product is a major cell-surface antigen, as well as a repressor of the other flagellin gene. When the promoter is inverted into the opposite orientation, the unlinked flagellin gene is transcribed because of the absence of its repressor. Two recombination sites, hixL and hixR, are located at the boundaries of the inverti ble segment (see Fig. 1A). Hin di mers bound to these sites can interact to form an inactive 'paired-hix' synaptic complex (Heichman and Johnson 1990). For recombination to occur, the synaptic complex must assemble at a 65-bp recombination enhancer located on the same DN A molecule, forming an 'invertasome' that is capable of initiating catalysis. DNA supercoiling is required to juxtapose correctly the three sites at the base of a plec- 

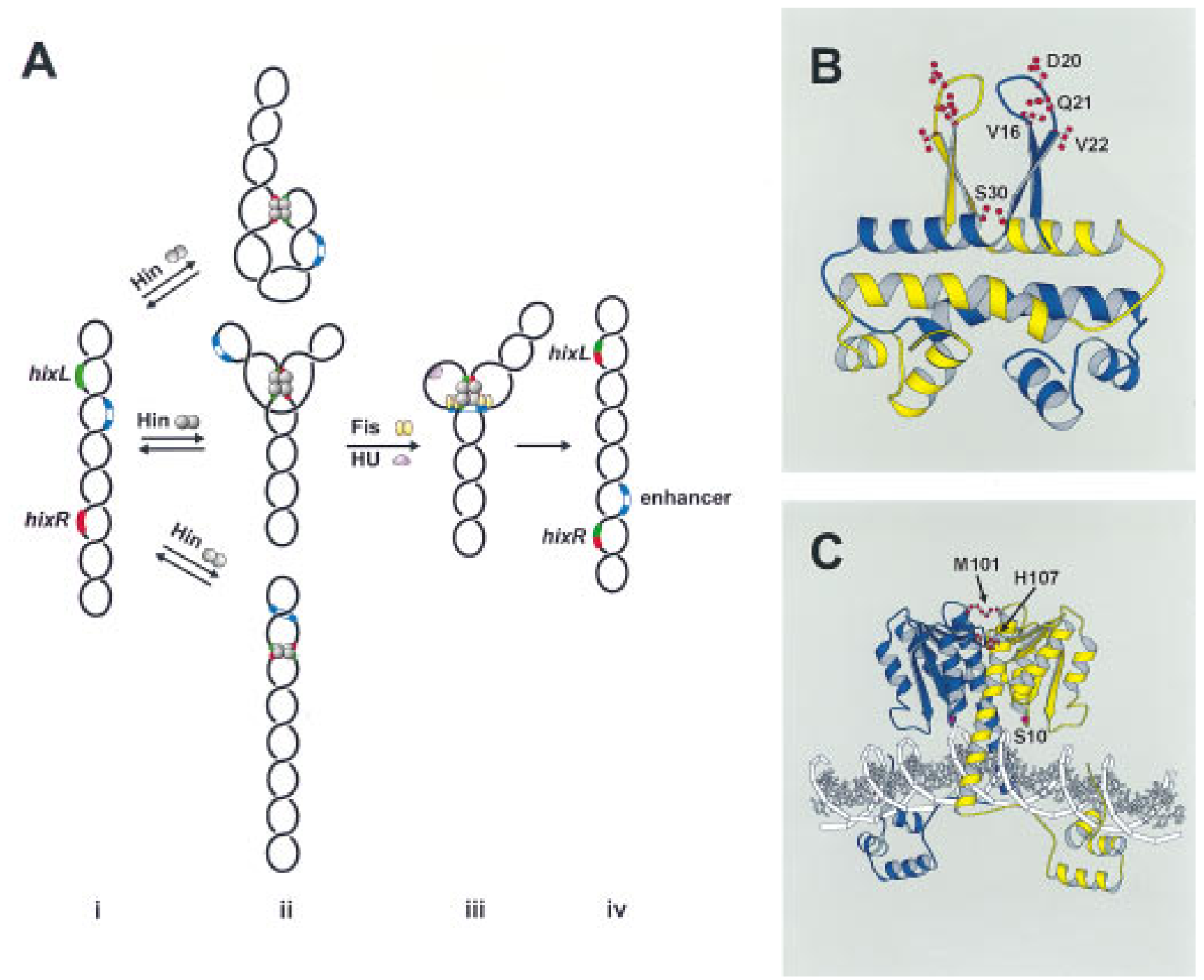

Figure 1. Hin-catalyzed site-specific DNA inversion. (A) Pathway of invertasome assembly. (i) The supercoiled plasmid substrate contains two recombination sites hixL and hixR and a recombinational enhancer containing two Fis-binding sites. (ii) Hin binds to hixL and hixR and can assemble these sites into a relatively unstable paired-hix complex by random collision. Several types of structures that can form are depicted schematically, as shown by topological studies on the Gin M $114 \mathrm{~V}$ and Hin H107Y mutants that can catalyze recombination in the absence of Fis (Crisona et al. 1994; S.K. M erickel and R.C. Johnson, unpubl.). (iii) Assembly of an invertasome containing hixL and hixR associated with the enhancer segment bound by two Fis dimers in a topologically defined structure at the base of a plectonemic branch on DNA. The DNA-bending activity of HU protein facilitates this assembly when the enhancer is located close to one of the recombination sites. Fis activates $\mathrm{Hin}$ to initiate double-strand cleavage at hixL and hixR followed by exchange of DNA strands and ligation. (iv) Resolution of the invertasome after completion of strand exchange results in inversion of the orientation of the DN A segment between hixL and hixR. (B) Structure of the Fis dimer showing the locations of Val-16 (V16), Asp-20 (D20), GIn-21 (Q21), Val-22 (V22), and Ser-30 (S30) as reveal ed in the crystal structure of K36E (Safo et al. 1997). Val-16, Asp-20, GIn-21, and Val-22 are within the $\beta$-hairpin activating motifs, whereas the two Ser-30 residues are directly across from each other on the A/A' helices. (C) M odel of the Hin dimer bound to DN A (Haykinson et al. 1996) showing the locations of M et-101 (M 101), His-107 (H107), and the active site residue Ser-10 (S10).

tonemic DNA branch and provide the energy to overcome otherwise weak Fis-Hin interactions (Kanaar et al. 1988; Heichman and Johnson 1990; Kanaar and Cozzarelli 1992). The hix sites within the active invertasome complex are oriented in the appropriate configuration to generate inversion of the intervening DNA upon exchange of DN A strands (Kanaar et al. 1990; M oskowitz et al. 1991). The requirement for a recombinational enhancer to be in the general vicinity of hixL and hixR also provides an additional level of specificity by decreasing the probability of undesired DNA rearrangements be tween psuedo recombination sites.

The recombinational enhancer consists of two essential binding sites for the Fis protein whose positions relative to each other are critical for enhancer function Johnson and Simon 1985; Kahmann et al. 1985; Johnson et al. 1987). Fis is a homodimer contai ning two 98-amino acid subunits (Johnson et al. 1988; Koch et al. 1988). 
X-ray crystallography has shown that each subunit contains four $\alpha$-helices that associate in the dimer to generate a compact ellipsoid core with the carboxy-terminal helices forming a helix-turn-helix DNA-binding motif (Kostrewa et al. 1991; Y uan et al. 1991). A recent crystal structure of a mutant Fis has revealed that previously unresolved amino acids 12-26 near the amino terminus of each subunit form a $\beta$-hairpin arm that protrudes over $20 \AA$ from the $\alpha$-helical core (Fig. 1B; Safo et al. 1997). Whereas the positions of the two $\beta$-arms in the dimer are fixed by crystal-lattice interactions, disulfide cross-linking between cysteines introduced at different positions within the $\beta$-arms demonstrate that the arms are mobile in solution. Extensive mutagenesis of this region has shown that three amino acids, Val-16, Asp-20, and Val22 , near the tip of the $\beta$-arm are critical for Fis activation of Hin inversion (Fig. 1B; Safo et al. 1997). Certain solvent-exposed amino acids within the $A \alpha$-helix may al so contact $\mathrm{Hin}$ within the invertasome structure.

$\mathrm{Hin}$ is a member of an extended family of resolvases and DN A invertases that share extensive amino aci d homology, particularly over the catal ytic and dimerization domains that constitute the amino-terminal threefourths of the protein (Sherratt 1989). The molecular structure of Hin bound to hix has been modeled from crystal structures of the Hin DNA-binding domain and $\gamma \delta$ resolvase complexes with DNA (Fig. 1C; Feng et al. 1994b; Rice and Steitz 1994b; Yang and Steitz 1995; Haykinson et al. 1996). Crystal structures of the $\gamma \delta$ resolvase dimer show that the active site serines within the catalytic domain of each subunit are not positioned appropriately to initiate site-specific cleavage of DNA (Rice and Steitz 1994b; Y ang and Steitz 1995). This implies that a conformational change that repositions the active site close to the scissile phosphodiester bonds must precede DNA cleavage. Several pieces of evidence suggest that a quaternary change in the dimer interface accompanies catalytic activation. The dimeric contacts are primarily between the long $\alpha$-helix (helix E) in each subunit that also traverses the DNA to connect to the DNA binding domain (Yang and Steitz 1995). When disulfide crosslinks are formed between cysteines introduced into the amino-terminal end of helix E, thereby restricting movement between subunits, catalytic activity is abolished, though resolvase or $\mathrm{Hin}$ binding to DN A is unaffected (Hughes et al. 1993; Lim 1994; Haykinson et al. 1996). Recombination by helix E cysteine mutants is no longer sensitive to oxidation once Fis-Hin interactions occur in an invertasome complex (Haykinson et al. 1996). These data imply that activation by Fis induces a conformational change directly or indirectly within the $\mathrm{Hin}$ dimer interface. Further support for the regulatory importance of the dimer interface comes from the observation that certain detergents that impai $\mathrm{H}$ in-dimer interactions enhance Hin-mediated DNA cleavage and that certain amino acid substitutions within the region lead to hyperactive DNA invertase mutants, which can promote recombination in the absence of Fis or a recombinational enhancer (Haffter and Bickle 1988; Klippel et al. 1988a; Haykinson et al. 1996). Most substitutions within this region, however, inhibit catalysis even though they are well separated from the active site pocket (Lim 1994; Haykinson et al. 1996).

DNA inversion proceeds in two experimentally separable chemical steps once the invertasome has been assembled. In the first step, the four $\mathrm{H}$ in subunits bound to the synapsed hix sites mediate a coordinated DNA attack to create a 2-bp staggered double-strand break at the center of each site (Johnson and Bruist 1989). In this process, invertase subunits become covalently joined to each $5^{\prime}$ end of the broken strands via an ester linkage at serine 10 (Klippel et al . 1988b). In the second step, DNA strand exchange, the cl eaved DN A strands are positi oned into the recombinant configuration and the DNA is religated through reversal of the protein-DNA linkage. Whereas the cl eavage and strand-exchange steps are normally highly concerted, reactions performed in the absence of magnesium and presence of ethylene glycol stall at the cleaved intermediate stage (Johnson and Bruist 1989). The enhancer remains associated with the Hin invertasome throughout the course of the reaction, though it can be released prior to ligation under certain conditions for Hin and readily for the Gin DNA invertase (Kanaar et al . 1990; Heichman et al. 1991; Crisona et al. 1994). Thus, whereas the Fis-bound enhancer sequence is required to initiate catalysis, it is not required for the final chemical step.

In this paper we address how Fis and Hin communicate to initiate the coordinated attack of the DNA strands. Specifically, we examine whether one or both of the activating $\beta$-hairpin arms in a Fis dimer are required to activate $\mathrm{Hin}$ and whether all or a subset of the Hin subunits must be activated directly by Fis. To investigate these issues, we employ homodimer and heterodimer mixes of different Fis and Hin mutants. Surprisingly, we find that only one functional $\beta$-hai rpin activating arm is requi red in each Fis dimer to activate $\mathrm{Hin}$. In contrast, the data indicate that each of the Hin subunits must be activated prior to initiation of any DN A chemistry, though they need not be proficient in catalysis. We also present a molecular model for the invertasome that is consistent with past and present information on its structure.

\section{Results}

Two activating Fis dimers are required to initiate recombination by $\mathrm{Hin}$

We have established previously that Fis dimers must be associated with both binding sites within the hin enhancer to form activated invertasomes. This was demonstrated by (1) mutagenesis studies showing that removal of either binding site or changes in the spacing between binding sites essentially abolish Fis-activation of inversion; (2) electron microscopy showing the absence of invertasome structures on substrates containing only one Fis binding domain; and (3) stoi chi ometry measurements indicating two Fis di mers per activated invertasome Johnson and Simon 1985; Bruist et al. 1987; 
Table 1. Fis and Hin mutants used in this work

\begin{tabular}{|c|c|c|}
\hline Mutant & Relevant properties & Source \\
\hline \multicolumn{3}{|l|}{ Fis } \\
\hline Q21C & $\begin{array}{l}\text { conditionally defective in } \\
\text { Hin activation: inactive } \\
\text { when oxidized; active } \\
\text { when reduced }\end{array}$ & Safo et al. (1997) \\
\hline D20K & defective in Hin activation & Safo et al. (1997) \\
\hline S30C & $\begin{array}{l}\text { active for Hin activation } \\
\text { when reduced or } \\
\text { oxidized }\end{array}$ & Safo et al. (1997) \\
\hline \multicolumn{3}{|c|}{ - } \\
\hline S10G & $\begin{array}{l}\text { catalytic active site } \\
\text { mutant }\end{array}$ & $\begin{array}{l}\text { M. Lainé and R. } \\
\text { Johnson }\end{array}$ \\
\hline M 101C & $\begin{array}{l}\text { conditionally defective in } \\
\text { Hin activity: inactive } \\
\text { when oxidized; active } \\
\text { when reduced }\end{array}$ & $\begin{array}{l}\text { Haykinson et al. } \\
\text { (1996) }\end{array}$ \\
\hline H107Y & $\begin{array}{l}\text { Fis-independent } \\
\text { recombination }\end{array}$ & $\begin{array}{l}\text { Haykinson et al. } \\
\text { (1996); this paper }\end{array}$ \\
\hline
\end{tabular}

Johnson et al. 1987; Heichman and Johnson 1990). It has not been determined, however, if both Fis dimers are requi red to activate $\mathrm{Hin}$ protomers to catalyze inversion in addition to performing structural roles in organizing or stabilizing the invertasome complex. For example, both dimers may be required to assemble an invertasome with the correct DNA topology, but the activating amino-terminal region of only one dimer may be sufficient to initiate catalysis.

To determine whether the amino-terminal activating $\beta$-arms are requi red on both Fis di mers to activate $\mathrm{Hin}$ in an invertasome complex, mixing experiments were performed with active and inactive Fis mutants, whose salient properties are listed in Table 1. Fis S30C, which forms a disulfide linkage between the two subunits within the $\mathrm{A} \alpha$-helices when oxidized ( $\left(\mathrm{S}^{\circ} \mathrm{C}^{\mathrm{O}}\right)$,wasused for the active protein (Fig. 1B; Safo et al . 1997). The Cys30 covalent linkage does not affect any activities of Fis but prevents the exchange of subunits between dimers, which readi ly occurs in solution (S.K. M erickel and R.C. Johnson, unpubl.). The conditionally active Fis mutant Q21C displays near wild-type activity when reduced $\left(\mathrm{Q} 21 \mathrm{C}^{\text {red}}\right)$. However, it is inactive for stimulating Hin inversion when oxidized (Q21C ${ }^{\circ \times}$ ) because of distortion of the $\beta$-hairpin loops by the Cys-21 disulfide bond (Fig. 1B and 2, lanes 4 and 5; Safo et al. 1997). DN A binding and transcriptional activation are not affected by the disulfide linkage.

Oxidized or reduced Q21C was added to Hin cleavage reactions contai ning limiting amounts of S30C ${ }^{\circ x}$ (Fig. 2). If the activation domains of only one of the two Fis dimers in an invertasome complex are sufficient to cataIytically activate $\mathrm{Hin}$, the addition of Q21C ${ }^{\circ x}$ to reactions containing limiting $\mathrm{S} \mathrm{CC}^{\text {ox }}$ would result in an increase in cleaved invertasomes over that observed from $\mathrm{S} \mathrm{CC}^{\mathrm{ox}}$ al one. This increase in activity would be derived from invertasome complexes that contain one active and one inactive Fis dimer. However, if functional amino- terminal arms are required in both Fis dimers to form an activated invertasome complex, the amount of Hincleavage products would not increase with the addition of Q21C ${ }^{\text {ox }}$. When limiting amounts of S30C ${ }^{\text {ox }}$ (Fig. 2, lane 1) were supplemented with an equival ent amount of S30C ${ }^{\text {ox }}$ (lane 2) or Q21C red (lane 6), a similar increase in activity was observed, reflecting the expected increase in the number of activated invertasome complexes formed. In contrast, when the limiting activity of S30C is supplemented with an equivalent amount of Q21C ${ }^{\text {ox }}$ (lane 3), the yield of Hin-cleavage products decreased slightly. The amount of singl ehix site cl eavage, which could have reflected catalytic activation of one Hin dimer by one Fis dimer, did not increase under these conditions. The same result is observed when the limiting activity of $\mathrm{S} \mathrm{C}^{\text {ox }}$ is supplemented with D20K (lane 7) or D20G (data not shown), which contain inactivating amino acid

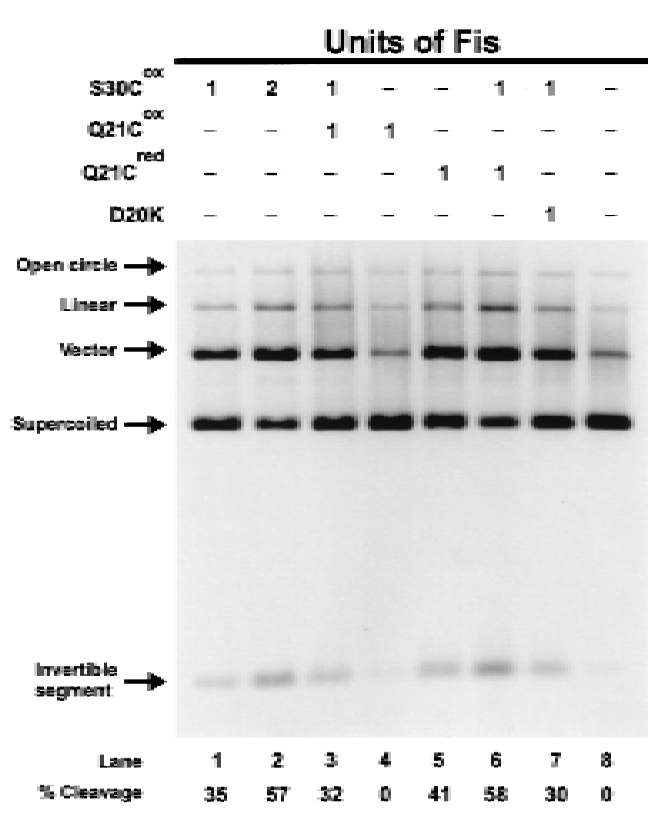

Figure 2. Activation of $\mathrm{Hin}$ by homodimer mixes of active and inactive Fis mutants. In vitro cl eavage reactions were incubated for $15 \mathrm{~min}$ in the absence of DTT. The units of Fis homodimer mutants used in each reaction are indicated above the lanes. One unit of Fis is defined as the limiting amount of Fis (in its active form) required to stimulate $\sim 30 \%$ cleavage in a $15-\mathrm{min}$ cleavage reaction, which reflects final yields. An equivalent amount (4 ng) of Fis D20K was added in lane 7. The percent of cleavage activity is indicated below each lane with the no Fis basal activity (14\%, lane 8$)$ subtracted. The locations of the primary Hin cleavage products, the vector, and invertible segment bands result from double-strand cleavage at both hix sites, are denoted al ong with the supercoiled plasmid substrate. $\mathrm{N}$ ormal Hin-catalyzed DNA cleavage reactions generate a small amount of double-strand cl eavage at a single hix site generating linear plasmids and no increase over the starting level of singlestrand cleaved open circle DNA. The lack of any increase in cleavage products in lanes 3 and 7 over lane 1 indicates that enhancers containing a Fis homodimer with mutated $\beta$-arm regions (Q21C ${ }^{\text {ox }}$ or D20K) plus a fully active Fis dimer (S30C) are not capable of assembling active invertasomes. This and subsequent ethidium bromide-stained gels are printed in reverse contrast. 
substitutions at the critical aspartic acid in the $\beta$-hairpin arms (Fig. 1B; Safo et al. 1997). These experiments indicate that both Fis dimers must contain a functional $\beta$ arm region to form a catalytically active invertasome complex.

Only one functional $\beta$-hairpin arm within a Fis dimer is required to activate $\mathrm{Hin}$

To ascertain whether the $\beta$-hairpin arms of both subunits within each Fis dimer are required to activate $\mathrm{Hin}$ inversion, heterodimers composed of one subunit with an active $\beta$-arm and one subunit with an inactive $\beta$-arm were constructed. Purified preparations of S30C and D20K/S30C/His, a carboxy-terminally His-tagged Fis containing the S30C mutation and the inversion-inactivating mutation D20K, were mixed, denatured under reducing conditions, and renatured to form a mixture of heterodimers and the two homodimeric forms (see Fig.
3A). The resulting dimers were stabilized by covalently linking the subunits through a disulfide bond at Cys-30 under oxidizing conditions. The S30C:D20K/S30C/ $\mathrm{His}^{\mathrm{ox}}$ heterodimers, along with the inactive D20K/ $\mathrm{S} 30 \mathrm{C} / \mathrm{His}^{\text {ox }}$ homodimers, were then separated from the active $\mathrm{S} 30 \mathrm{C}^{\circ}$ homodimers by nickel chromatography. Nonreducing SDS-PAGE demonstrated that S30C:D20K/S30C/His ${ }^{\circ \mathrm{x}}$ heterodimers constituted $\sim 75 \%$ of the protein in the imidazole-eluted fraction with no detectable S30C ${ }^{\text {ox }}$ homodimers. Figure 3, B and $\mathrm{C}$, shows the results of $\mathrm{H}$ in cleavage and inversion reactions performed with the renatured mix before and after the nickel chromatography step. The purified S30C:D20K/S30C / His ${ }^{\circ \times}$ heterodimer fraction efficiently activated $\mathrm{Hin}$ in both reactions (Fig. 3B,C; Iane 1), demonstrating that only one active $\beta$-hai rpin arm in each Fis dimer is sufficient to activate a Hin dimer. Detectable amounts of nicked products that could have arisen from single-strand cl eavages at one or both hix sites were not

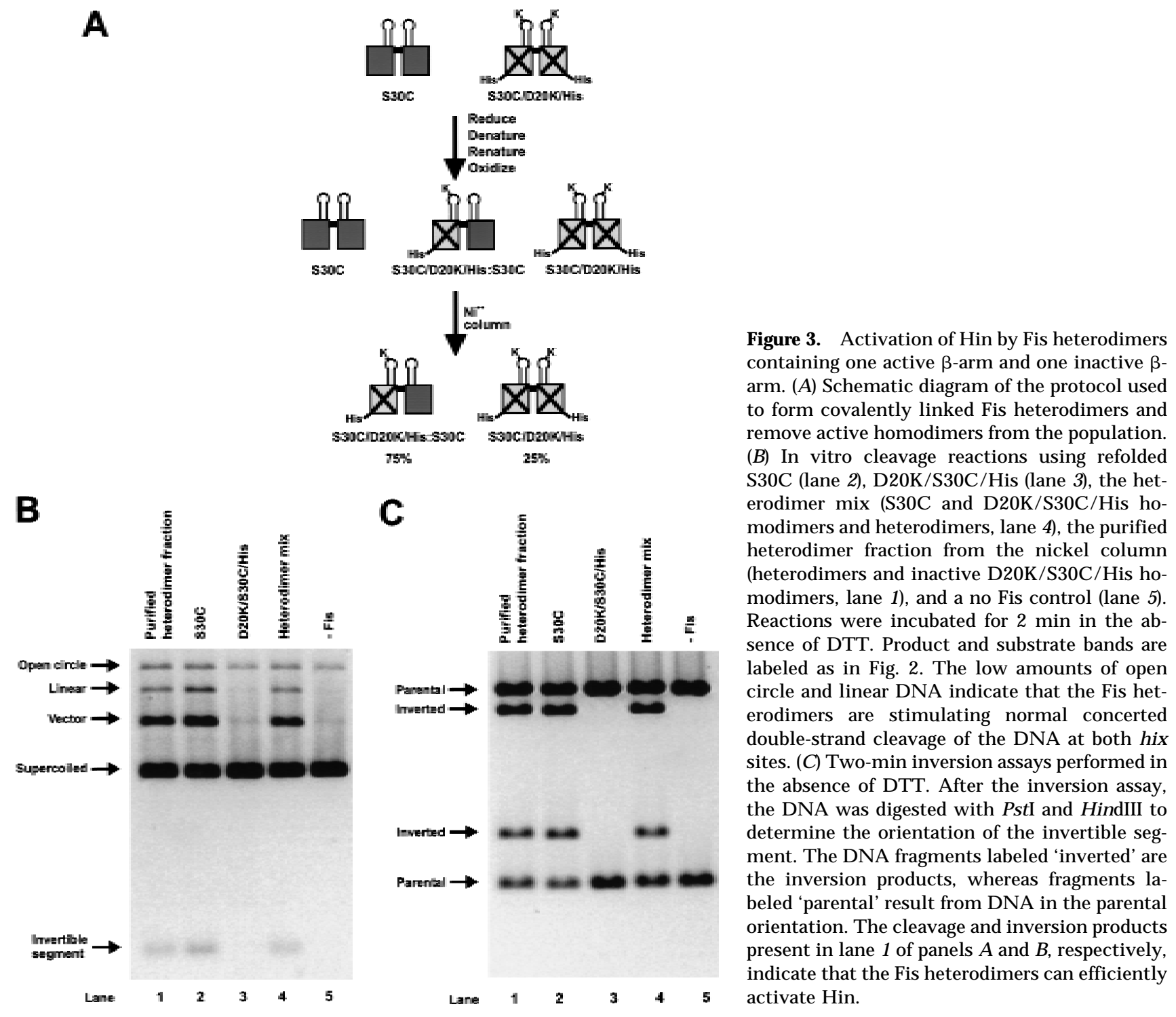


generated from these reactions. The same result was obtained in experiments employing heterodimers in which one of the subunits was deleted for the entire $\beta$-hairpin Ioop [Fis $\Delta(17-21)$ ] (data not shown).

\section{Properties of Hin mutants used to investigate} Hin activation

To investigate the mechanism of Hin activation, several Hin mutants that either block the reaction at particular steps or catalyze recombination without activation by Fis were examined. Their relevant properties are summarized in Table 1. Hin S10G is mutated at the serine nucleophile that attacks the DN A phosphodiester during the first chemical step of the recombination reaction (Fig. 1C) and consequently displays no DNA cleavage activity (e.g., Fig. 5B, lane 3, below). Unlike other substitutions at this position (Adams et al. 1997), S10G has no detrimental effect on hix binding ( $M$. Lainé and R.C. Johnson, unpubl.) and synapsis (Fig. 4, lane 4), which is assayed by the formation of paired-hix complexes after glutaraldehyde cross-linking and gel electrophoresis (Heichman and Johnson 1990). Additionally, we provide evidence below that Fis-activation within an invertasome remains unaffected in this mutant. Thus, S10G is blocked specifically at the step of DNA cleavage.

Methionine 101 is predicted to be located at the

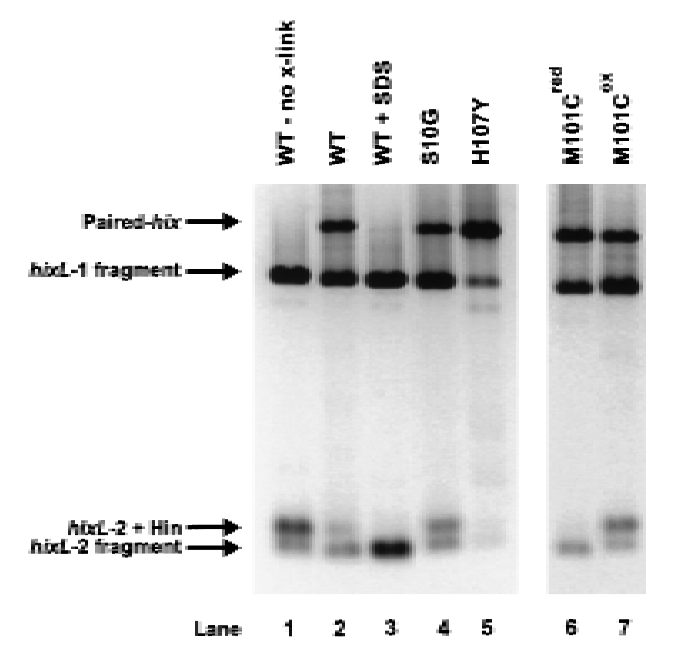

Figure 4. Formation of synaptic complexes by Hin mutants. In vitro paired-hix assays were performed on the Hin proteins employed in the mixing experiments. Using pM S634, which contains two hixL sites (hixL-1 and hixL-2), Hin cleavage reactions were cross-linked with glutaral dehyde, digested with Pstl, and el ectrophoresed in an agarose gel. In lane 1 glutaral dehyde was not added to the reaction, and in lane 3 SDS was added to a final concentration of $0.7 \%$ immediately prior to loading on the gel. The Hin proteins used in each assay are indicated above the lanes. The location of the paired-hix complex as well as the unpaired hixL DN A fragments are indicated. Hin binding to the smaller Pstl fragment containing hixL-2 results in a slower migrating complex, but Hin binding to the larger Pstl fragment containing hixL-1 cannot be resolved as a separate complex in this gel. M 101C ${ }^{\circ x}$ was generated by long-term storage in $<1 \mathrm{~mm}$ DTT and contained $90 \%$ disulfide-linked dimers. amino-terminal end of the $\mathrm{E} \alpha$-helix within the dimer interface (Fig. 1C). A cysteine at this position readily forms a disulfide linkage between the two dimer subunits (M 101C ${ }^{\text {ox }}$ ) (Lim 1994; Haykinson et al. 1996). M 101C is conditionally defective for basal and Fis-activated recombination. Under oxidizing conditions, hix cleavage and subsequent DN A exchange is blocked, but hix binding (Lim 1994; Haykinson et al. 1996) and synapsis (Fig. 4, lane 7) by $\mathrm{M} 101 \mathrm{C}^{\mathrm{ox}}$ remain efficient. Under reducing conditions, $\mathrm{M} 101 \mathrm{C}$ displays near-normal Fisdependent inversion ( $M 101 C^{\text {red }}$ ). Coval ent linkage of the $\mathrm{Hin}$ dimer probably prevents a quaternary change involving the dimer interface that is required for catalytic activation (Hughes et al. 1993; Lim 1994; Haykinson et al. 1996). Experiments measuring the kinetics of hix cleavage and disulfide formation upon a shift of M101C to oxidizing conditions indicate that oxidative modifications that do not result in a disulfide linkage al so effectively block catalysis (data not shown; Fig. 6, below).

Gain-of-function mutants that support recombination in the absence of Fis have been isolated and characterized in the Gin, Cin, and Hin DNA invertases (Haffter and Bickle 1988; Klippel et al. 1993; Haykinson et al. 1996). H107Y is the strongest Hin mutant isolated to date that can promote in vivo and in vitro recombination without Fis. H107Y catalyzes efficient hix cleavage in the absence of Fis, under standard conditions (e.g., Fig 6, $C$ and D, lanes 1 and 2, below). Like the Fis-activated wild-type reaction, DN A cleavage by $\mathrm{H} 107 \mathrm{Y}$ without Fis activation appears concerted between hix sites and primarily double-strand cuts are generated at each site. Thus, hix cleavage by $\mathrm{H} 107 \mathrm{Y}$ occurs within the context of paired-hix complexes, which form efficiently and are very stable (Fig. 4, lane 5). H107Y remains further activatable by Fis because cleavage and inversion rates are increased when Fis is present (Fig. 6C, lanes 1 and 2, below; data not shown), indicating that His-107 is probably not directly contacted by Fis. Histidine 107 is located in the $E$-helix region, but unlike $M$ et-101, its imidazole ring is predicted to be oriented towards residues 92-93 of the partner subunit within the dimer (Fig. 1C). We postulate that His-107 may be making an important regulatory contact within the dimer that modulates $\mathrm{Hin}$ activity in response to Fis.

Both Hin dimers must be activated to initiate hix cleavage

To determine whether both Hin dimers bound to the synapsed hix sites within an invertasome must be activated for any catalysis to occur, we performed reactions containing different combinations of $\mathrm{Hin}$ proteins. The $\mathrm{Hin}$ proteins were added sequentially to minimize potential subunit mixing prior to hix site binding. Previous studies have shown that Hin forms a very stable dimer once bound to hix (Glasgow et al. 1989a). In addition, control experiments were performed in which (1) Hin binding to a labeled fragment was followed by gel-mobility shift assays after competition with excess Hin recombination substrate DNA, and (2) Hin recombination 
was measured in reactions in which a second substrate was added after prebinding to the first substrate. These experiments indicated that once bound, $\mathrm{Hin}$ does not exchange between hix sites during the time frame of the $\mathrm{Hin}$ reactions performed below (data not shown).

Mixtures of Hin-WT and M 101C ${ }^{\circ}$, were assayed to determine whether both Hin dimers in an invertasome must be activatable to observe any cleavage activity. In Figure 5A, a limiting amount of disulfide-linked $\mathrm{M} 101 \mathrm{C}^{\mathrm{ox}}$ was bound to the substrate DN A, resulting in substrates containing two hix-bound Hin dimers, one hix-bound Hin dimer, or no hix-bound Hin dimers. The cleavage reaction was then supplemented with an equivalent amount of Hin-WT and initiated by the addition of Fis. The activity of M 101C red was assayed by reducing the DNA-bound $M 101 C^{\circ}$ into an activatable form with $5 \mathrm{~mm}$ DTT. Prebinding of covalently linked M 101C ${ }^{\text {ox }}$ dimers hel ped to ensure that subunit mixing between $\mathrm{Hin}$ dimers did not occur. As expected, theyiel d of cleavage products from M 101C red plus Hin-WT (Fig. $5 \mathrm{~A}$, lane 3) was increased over that obtained with HinWT or M 101C red (lanes 1,5$)$ and similar to the $2 \times \mathrm{Hin}-$ WT (lane 2) controls. However, no increase in the reaction was observed with M 101C ${ }^{\text {ox }}$ plus Hin-WT (lane 4). Significantly, this reaction did not produce an increase in single hix cut (double stranded or nicked) products that could have been produced by invertasomes containing one active Hin-WT and one inactive M101C ${ }^{\circ}$ dimer. These results imply that both Hin dimers that participate directly in the reaction must be activatable for any hix cleavage to occur.

M ixing experiments were also performed with the active site mutant S10G and Hin-WT. Limiting amounts of SIOG were bound to the substrate followed by the addition of Hin-WT, and the nature of the Hin cleavage products in the presence of Fis was determined. If S10G is competent for activation, but defective in catalysis, invertasomes containing one Hin-WT dimer and one S10G dimer would be expected to be catalytically active but cleave only one of the hix sites in the substrate. As shown in Figure 5B, lane 2, single hix cut plasmids accumulated in the S10G plus Hin-WT reaction. This result demonstrates that activation and cleavage can be mechanistically separated. Although both Hin dimers bound to the hix sites must be activatable, DNA cleavage by both dimers is not necessary to observe catalytic activity.

Both subunits within the Hin dimer bound to hix must be activated to initiate catalysis

Hin heterodimers were used to determine whether both subunits in a Hin dimer must be activatable to initiate catalysis. Equal amounts of M101C and Hin-WT were denatured and refolded together under dilute conditions in the presence of high concentrations of CHAPS to generate heterodimers. The heterodimer mix was assayed for cleavage activity after a brief incubation with oxidized glutathione. Under these oxidation conditions, M 101C subunits can be inactivated by oxidative modifications at individual Cys-101 residues, but $\mathrm{Hin}-\mathrm{WT}$ activity is not affected (Fig. 6B, lane 2). If Hin-WT subunits in M 101C ${ }^{\circ}$ :H in-WT heterodimers are unable to become activated and cleave DN A, we would expect to observe only a small amount of double-strand cleavage at both hix sites as depicted in scenario 1 of Figure 6A (top). However, if Hin-WT subunits are able to cleave the DNA even when associated with nonactivatable
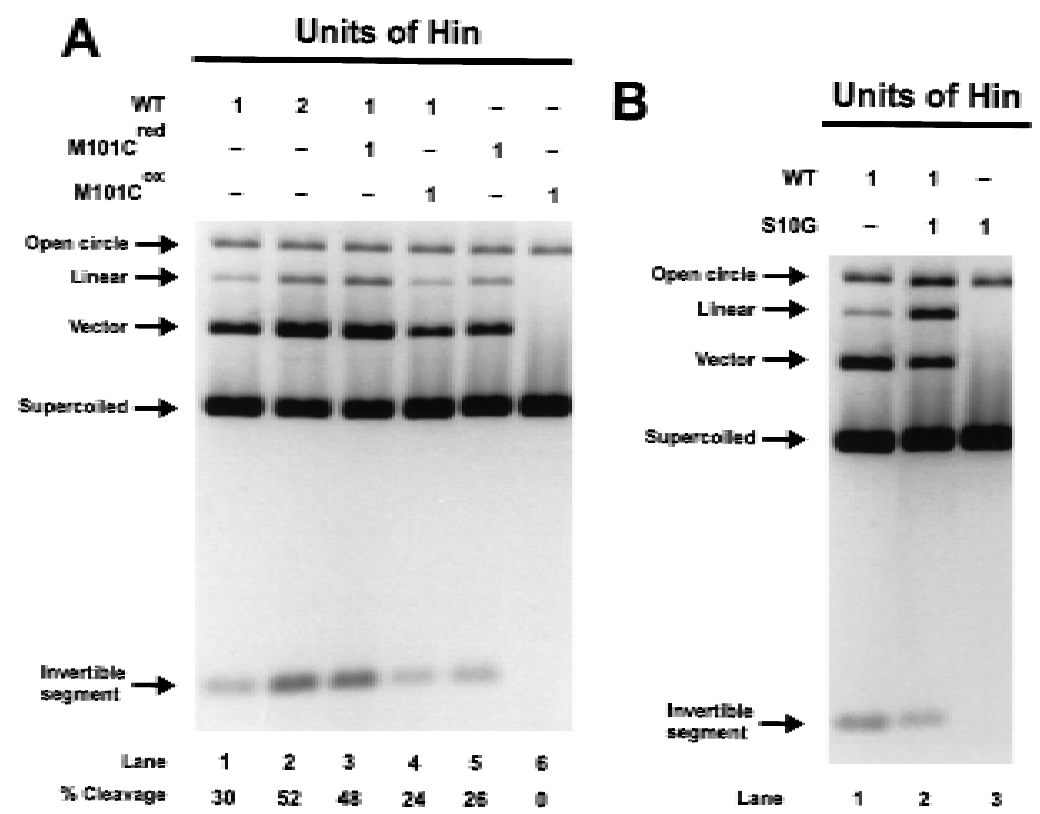

Figure 5. Activity of homodimer mixes of wildtype and inactive Hin mutants in the presence of Fis. (A) Reactions employing M 101C and Hin-WT. The units of Hin homodimers used in each 15-min in vitro cleavage reaction are indicated above the lanes. One unit of Hin was empirically determined as the limiting amount of Hin (in its active form) required to produce $\sim 30 \%$ cleavage in a $15-\mathrm{min}$ cleavage reaction. To prevent potential subunit exchange in solution, Hin homodimers were added sequentially. The activity of $M 101 C^{\text {red }}$ was assayed by prebinding $\mathrm{M} 101 \mathrm{C}^{\circ}$ to the $\mathrm{DN} \mathrm{A}$, reducing with $5 \mathrm{~mm}$ DTT for $1 \mathrm{~min}$ at $37^{\circ} \mathrm{C}$, and starting the reaction with Fis. The percentage of cleavage activity is indicated below each lane. The lack of any increase in cl eavage products in lane 4 as compared to lane 1, particularly single hix-cleaved linear plasmids, indicates that activated invertasomes containing Hin-WT and M 101C ${ }^{\text {ox }}$ homodimers are not formed. (B) Reactions employing SIOG and HinWT homodimers. For S10G, one unit was taken as the equivalent amount of $\mathrm{Hin}(20 \mathrm{ng})$ required to generate 1 unit of Hin-WT activity, because the catalytic activity of S10G could not be measured.

This may result in slightly more functional S10G than Hin-WT, as S10G appears to have a slightly greater specific activity with respect to hixL binding than Hin-WT. The presence of enhanced levels of single hix-cleaved linear plasmids in lane 2 demonstrates that activated invertasomes containing Hin-WT and S10G homodimers are forming. 
Figure 6. Activity of Hin heterodimers. (A) Schematic diagrams illustrating the combinations of $\mathrm{Hin}$ dimers found in invertasome complexes formed in the Hin heterodimer mix assays. The Fis-bound enhancer has been omitted for clarity. The relative amounts of each type of complex predicted to form in the heterodimer mix assays are indicated below the complex. (Top) Predicted results from M $101 \mathrm{C}^{\mathrm{ox}}+$ Hin-WT heterodimer mixing assays. (Dark, solid circles) Hin-WT subunits; (light circles containing an $X$ ) inactive M 101C ${ }^{\text {ox }}$ subunits. Scenario 1 depicts the predicted results if a Hin-WT subunit in a M 101C ${ }^{\circ x}$ :Hin-WT heterodimer is unable to become activated and cleave the DNA. Scenario 2 describes the predicted products from each complex if a Hin-WT subunit in a M 101C ${ }^{\text {ox: }} \mathrm{Hin}$-WT heterodimer becomes activated and cleaves the DNA. The predicted activities of complexes containing an inactive $\mathrm{M} 101 \mathrm{C}^{\mathrm{ox}}$ homodimer are based on the results from the $M 101 C^{\circ x}$ homodimer mixing assays (Fig. 5A). The predicted activities shown below the arrows include (DC) double-strand cleavage at both hix sites; (N A) no activity; (LIN) linear DNA resulting from double-strand cleavage at only one hix site; and (NICK) nicked DNA resulting from single-strand cleavage at one or both hix sites. Scenario 1 is consistent with the results observed in the M101C ${ }^{0 x}: \mathrm{Hin}-\mathrm{WT}$ heterodimer mixing assays (Fig. 6B). (Bottom) Predicted results from S10G + Hin-WT heterodimer mixing assays. (Dark, solid circles) HinWT subunits; (light circles containing an asterisk) catalytically inactive S10G subunits. Scenario 1 indicates the predicted results if a Hin-WT subunit in a S10G:Hin-WT heterodimer cannot become activated and cleave the DN A. Scenario 2 shows the predicted activities if a Hin-WT subunit in a S10G:Hin-WT heterodimer becomes activated and cleaves the DN A. The predicted activities of complexes containing an inactive S10G homodimer are based on the result from the S10G homodimer mixing assays (Fig. 5B). Scenario 2 is consistent with the results observed in the S10G:Hin-WT heterodimer mixing assays (Fig. 6B). (B) T wo-min in vitro cleavage reactions empl oying denatured and refol ded Hin-WT (lanes 1,2,7), M101C + Hin-WT heterodimer mix (M 101C and Hin-WT homodimers and heterodimers; lanes 3,4), M 101C (Ianes 5,6), and SIOG + Hin-WT heterodimer mix (SIOG and Hin-WT homodimers and heterodimers; lane 8). All Hin mutants were allowed to bind to the DNA for $5 \mathrm{~min}$ at $37^{\circ} \mathrm{C}$ and the reactions were started with the addition of Fis. Hin-WT, M 101C, and the M 101C + Hin-WT heterodimer mix were bound to the substrate and assayed in reducing (Red) conditions containing 5 mM DTT or oxidizing (Ox) conditions containing $10 \mathrm{~mm}$ oxidized glutathione as indicated. The low amount of cleavage products generated by the M 101C ${ }^{\text {ox }}+$ Hin-WT preparation (lane 4) implies that invertasomes containing M 101C ${ }^{\text {ox }}$ :Hin-WT heterodimers are not catalytically active. The substantial amounts of single-strand hix cleavage (open circle) and double-strand cleavage at a single hix site (linear) produced by the S10G + Hin-WT preparation (lane 8) are indicative of invertasomes containing S10G:Hin-WT heterodimers and S10G + Hin-WT homodimers, respectively. (C) Two-min in vitro cl eavage assays of refol ded H 107Y homodimers and a H 107Y +S10G heterodimer mix ( $\mathrm{H} 107$ and S10G homodimers and heterodimers) performed in the presence or absence of Fis as indicated above the lanes. The formation of single-strand hix cleavage (open circle) and double-strand cleavage at a single hix site (linear) produced by the H107Y +S10G preparation in the presence of Fis (lane 4) is indicative of synaptic complexes containing H 107Y:S10G heterodimers and H107Y +S10G homodimers, respectively. The low amount of cleavage products generated in the absence of Fis (lane 3) implies that most catal ytic activity, including single-strand cl eavage from H107Y:S10G heterodimers, is dependent upon Fis. (D) Two-min in vitro cleavage reactions of refol ded $\mathrm{H} 107 \mathrm{Y}$, Hin-WT, and $\mathrm{H} 107 \mathrm{Y}+\mathrm{Hin}-\mathrm{WT}$ heterodimer mixes in which $\mathrm{H} 107 \mathrm{Y}$ and Hin-WT were mixed at 1:1 (lanes 5,6) and 1:2 (lanes 7,8) molar ratios before refol ding. Because H 107Y is more active than Hin-WT, these ratios overestimate the functional amount of $\mathrm{H} 107 \mathrm{Y}$. These preparations were assayed in the presence or absence of Fis as indicated above the lanes. $\mathrm{N}$ ote the strong stimulation by Fis with Hin-WT (lanes 3,4), but efficient cleavage by H107Y regardless of the presence of Fis (lanes 1,2) under these relatively long incubation times. Complexes assembled from the mixed populations appear to be stimulated strongly by Fis for catalytic activity, implying that $\mathrm{H} 107 \mathrm{Y}$ :Hin-WT heterodimers are not active even for single-strand cleavage without Fis. 
M 101C ${ }^{\text {ox }}$ subunits in heterodimers, we would predict that double-strand cleavage at one hix site and nicked products would also be generated as shown in scenario 2 of Figure $6 \mathrm{~A}$ (top). We find that Fis-activated reactions performed with M $101 C^{\circ}$ :Hin-WT heterodimer mixes only generate a trace of doublestrand cleavage (Fig. 6B, Iane 4), consistent with scenario 1 of Figure 6A (top). We interpret the small amount of activity present in the

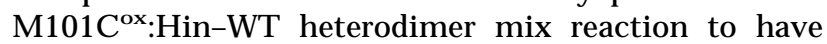
originated from invertasomes containing two wild-type $\mathrm{Hin}$ dimers. The oxidation-sensitive population contains at least one M 101C ${ }^{\circ}: \mathrm{Hin}-\mathrm{WT}$ heterodimer or M 101C ${ }^{\text {ox }}$ homodimer (Fig. 6A, top, scenario 1). The absence of an increase in nicked products in these reactions indicates that Hin-WT subunits within complexes containing M 101C ${ }^{\circ}: H i n-W T$ heterodimers do not catalyze singlestrand cleavage at hix at a detectable level (Fig. 6A, top, scenario 1).

Reactions performed with S10G:Hin-WT heterodimer mixes confirm that functional heterodimers are formed in the renaturing protocol and that a Hin dimer can be induced into an activated state without both subunits being catalytically competent. Scenario 1 of Figure $6 \mathrm{~A}$ (bottom) depicts the expected results if the Hin-WT subunit of an S10G:Hin-WT heterodimer is not able to become activated and cleave the DN A. Scenario 2 of Figure $6 \mathrm{~A}$ (bottom) illustrates the predicted results if S10G:Hin-WT heterodimers are able to become activated and the Hin-WT subunit is able to cleave the DN A even though the S10G subunit is catalytically deficient. Fis-activated S10G:Hin-WT heterodimer mix reactions generate a significant number of both nicked and linear DNA products (Fig. 6B, lane 8), representing singlestrand cleavage at one or both hix sites and double-strand cleavage at only one hix site, respectively. These results are consistent with the predicted types of products illustrated in scenario 2 of Figure 6A (bottom). The nicked DNA products would presumably be generated from invertasomes containing two S10G:Hin-WT heterodimers or one S10G:Hin-WT heterodimer and one S10G homodimer. This is the first experimental condition in which $\mathrm{Hin}$ has been found to generate singlestrand cleavages. Invertasomes generating linear products would contain one catalytical ly competent wild-type homodimer and one dimer containing at least one subunit of S10G. The presence of the nicked products indicates that only one subunit within a Hin dimer needs to be catalytically competent to observe cleavage products. The inactivity of the M $101 \mathrm{C}^{\mathrm{ox}} \mathrm{H}$ in-WT heterodimer, combined with the nicking activity of the S10G:Hin-WT heterodimers suggests that both subunits within the dimer must be activatable by Fis but not necessarily catalytically competent, to observe cleavage activity.

Reactions were also performed on heterodimer mixes of the Fis-independent mutant H107Y and either S10G or Hin-WT. Because H107Y is more active than wild type, even in the presence of Fis, molar equival ent mixtures of H107Y and Hin-WT or S10G probably functionally over-represent H107Y activity. As shown in Figure $6 \mathrm{C}$, reactions employing a heterodimer mix of $\mathrm{H} 107 \mathrm{Y}$ and S10G generated substantial amounts of nicked and linear products in the presence of Fis (lane 4), but little reaction was observed in the absence of Fis (lane 3). As discussed above, the presence of nicked DNA products confirms that heterodimers were present in these reactions. The Fis dependence of the H107Y:S10G heterodimer nicking activity demonstrates that both subunits in a Hin dimer must be either activated by Fis or contain a mutation conferring Fis independence to initiate catalysis. Thus, alteration of only one of the two dimer contacts invol ving residue 107 is not sufficient to induce Fis independence in the Hin dimer. Reactions employing H107Y:Hin-WT heterodimer mixes also displayed little activity without Fis, particularly in the 1:2 mixing reaction, but were activated by Fis to generate double-strand cleavages at both hix sites (Fig. 6D, lanes 5-8). The absence of single-strand nicking in the reactions without Fis indicates that a $\mathrm{H} 107 \mathrm{Y}$ subunit within a heterodimer is not capable of catalyzing cleavage unless the other subunit is activated by Fis.

\section{Discussion}

The initiation of the chemical steps of Hin recombination by the concerted nucleophilic attack of serine 10 in all four Hin subunits bound to the hix sites is regulated by two different protein-protein interactions within the invertasome: synaptic interactions between $\mathrm{H}$ in dimers and Fis-Hin interactions. The present work focuses on the role of Fis-Hin interactions in the regulation of coordinated catalytic activity of the Hin protomers.

Communication between Fis and Hin dimers

in the coordinate activation of the invertasome

We have shown previously that Fis dimers must be bound to both enhancer domains to activate DN A cleavage by Hin (Johnson and Simon 1985; Bruist et al . 1987). We show here that enhancers containing activating and nonactivating Fis dimers are incapable of assembling catalytically active invertasomes. Likewise, our experiments suggest that both Hin dimers bound to the synapsed hix si tes must be activatable to initiate the chemical steps of recombination. Invertasomes containing one activatable and one nonactivatable dimer do not promote any DNA cleavage. The lack of single hix site cleavage in these reactions strengthens the argument that the Hin dimers must communicate to coordinate their catalytic activities. Although we have not directly proven that invertasomes containing activatable and nonactivatable $\mathrm{Hin}$ dimers are assembling, we note that nonactivatabl e $\mathrm{M} 101 \mathrm{C}^{\circ \mathrm{x}} \mathrm{H}$ in di mers readily form pairedhix synaptic complexes. M oreover, addition of M 101C ${ }^{\text {ox }}$ strongly inhibits reactions containing saturating amounts of Hin-WT (data not shown). Taken together, the Fis and Hin dimer mixing experiments suggest that Fis must activate both of the synapsed Hin dimers to initiate any catal ysis.

The Hin homodimer mixing experiments al so demonstrate that activation and catalysis are biochemically 
separable events. Invertasomes assembled from wildtype Hin and a catalytic site mutant (Hin S10G) are cataIytically active but generate double-strand cleavages at only one hix site. Given the requirement discussed previously that both $\mathrm{Hin}$ dimers must be activatable to initiate catalysis, we interpret the single-site cleavage to imply that invertasomes containing mixtures of wildtype and S10G dimers can be activated even though only one dimer is catalytically competent. Experiments with $\gamma \delta$ resolvase have also shown that synaptic complexes containing a catalytic site mutant dimer and a wild-type dimer at the crossover sites generate double-strand cleavages at one res site (Boocock et al. 1995).

Communication between Fis and Hin subunits in the coordinate activation of the invertasome

Because the activation region of the Fis dimer contains two structurally independent and mobile $\beta$-hairpin arm motifs that protrude from the core, it is tempting to consider a model in which each $\beta$-arm contacts one of the four Hin subunits that are bound to a hix site in the invertasome to initiate recombination. However, we found that only one $\beta$-arm in each Fis dimer was sufficient to stimulate both Hin DNA cleavage and strand exchange. Reactions employing Fis heterodimers with only one active $\beta$-arm appeared to be as efficient as active homodimers in stimulating $\mathrm{Hin}$ inversion. The activity of the Fis heterodimers is entirely consistent with an earlier surprising observation that Fis dimers containing the two mobile $\beta$-arms linked together by a disulfide bridge at one of several positions within the $\beta$-strands or $\beta$-hai rpin loops (e.g., between amino acids 15, 18, and 19) were able to activate Hin efficiently (Safo et al. 1997). The covalent linkage would prevent the two $\beta$-arms from interacting simultaneously with two separate regions of the Hin dimer.

The requirement for only one of the two regulatory regions on a dimeric protein has also been described for transcriptional activation by the CRP protein, in which heterodimers composed of activating and nonactivating CRP subunits were found to potentiate transcription when the activating region was oriented appropriately with respect to the target RN A polymerase (Zhou et al. 1993, 1994). Whereas the very efficient activation by Fis heterodimers implies that they may function when bound in either orientation at each enhancer domain, this conclusion is tempered by the fact that catalytic activation, not invertasome assembly, is likely be the slow step in the Hin inversion reaction (Haykinson et al. 1996). Therefore, different binding arrangements of the Fis heterodimers could be sampled in the time frame required to initiate cl eavage. Directing the orientation of a Fis heterodimer using al tered binding specificity mutations, as was done with CRP, is probably not possible because of the degenerate DN A-recognition sequence.

The finding that only one of the Fis dimer $\beta$-arms is required to activate a $\mathrm{Hin}$ dimer led us to investigate whether activation of only one Hin subunit within a hix-bound dimer is sufficient to initiate recombination.
Using newly established methods for effectively refolding denatured $\mathrm{Hin}$, a series of different $\mathrm{Hin}$ mutant heterodimers were assayed for their ability to initiate re combination in the presence or absence of Fis. The results of these experiments are consistent with the conclusion that both Hin subunits within the dimer must be activated by Fis to initiate recombination. For example, invertasomes assembled using heterodimer mixes containing wild-type and the activation-defective M101C ${ }^{\circ}$ Hin subunits were not catalytically active, even for single-strand cl eavage at hix. On the other hand, Fis-activated reactions empl oying heterodimers containing the acti vatable catal ytic site mutant S10G pl us wildtype Hin generated substantial levels of nicked (as well as double-strand cleavages at one hix site) products. Thus, the catalytic activity of both subunits within the Hin dimer is coordinately activated by Fis prior to DNA cleavage.

Heterodimer mixes containing Fis-independent (H107Y) and Fis-dependent (S10G or wild-type) subunits were assayed to determine whether a single Fis-independent subunit could confer Fis-independence to a Hin dimer. These experiments suggested that complexes containing H107Y:S10G or wild-type heterodimers were only active in the presence of Fis. As was the case with the Fis-activatable:Fis-nonactivatable $\mathrm{H}$ in heterodimers, nicking by the hyperactive $\mathrm{H} 107 \mathrm{Y}$ subunit dimerized with a wild-type subunit was not observed. These results provide further support for the conclusion that both subunits within the Hin dimer must be in an activated state to initiate hix cleavage.

Potential mechanisms of Hin dimer activation by a single $\beta$-hairpin arm on Fis

There are several possi ble mechanisms by which a single Fis $\beta$-arm could activate both subunits of a $\mathrm{H}$ in dimer within the invertasome. In one model, a Fis $\beta$-arm could interact sequentially with a common site in each Hin subunit. Once one Hin subunit has been activated, the mobile $\beta$-arm would move to contact the second subunit. Such a movement, however, would seem unlikely within the context of an assembled invertasome (see model below), as the $\beta$-arm would need to swing around to the opposite side of the Hin dimer to contact the analogous position within the symmetrically oriented subunit. Moreover, reactions employing Fis heterodimers do not generate detectable levels of nicked DNA intermediates, which could arise from activation of the first Hin subunit prior to the second. A second model predicts that one Fis $\beta$-arm interacts with only one Hin dimer subunit, perhaps triggering a conformati onal change, which in turn, induces a similar change in the second dimer subunit to result in a coordi nate attack of the hix DNA. Whereas this type of sequential activati on mechanism al so remains possible, we do not favor it because of the data implying that both Hin subunits within the dimer must be either activated by Fis or contain the Fis-independent activating mutation to initiate catalysis. In a third model, a single Fis $\beta$-arm contacts 
Hin within or adjacent to the dimer interface in such a way as to trigger a simultaneous conformational change in both subunits. This quaternary change would result in the repositioning of the active sites of both Hin subunits to enable a coordi nate attack of both DN A strands at the center of the hix sites (Feng et al. 1994a; Rice and Steitz 1994b). In this regard, the consequence of Fis-Hin interactions may resemblethe situation found with the single amino acid substitutions within the dimer interface (such as H107Y) that allow the DNA invertases to promote recombination without Fis.

\section{Structural model of the Hin invertasome}

We have constructed a molecular model for the Fis-Hin invertasome complex that provides a framework for further elucidating the mechanism of Fis-Hin and $\mathrm{Hin}-\mathrm{Hin}$ communication during the process of DNA inversion. Previous studies place a number of constraints on the structure of the invertasome that must be satisfied. The spacing of the two Fis-binding sites within the enhancer, 48 bp between their centers, is critical for enhancer function. Whereas addition of one complete helical turn of DNA is partially tolerated, addition of more than one helical turn, deletion of one turn, or addition of a partial helical turn essentially destroys enhancer activity (Johnson et al. 1987; R.C. Johnson, unpubl.). Fis-induced DNA bending angles and the path of DNA when bound at the hixL proximal and distal binding sites in the enhancer have been determined by gel mobility shift assays and from mapping the locations and efficiencies of scission sites by different Fis-1,10 phenanthroline chimeras (Pan et al. 1996; Perkins-Balding et al. 1997). For both binding sites, Fis-1,10 phenanthroline copper cleavage data have shown that the DNA flanking the core Fisbinding sites that is oriented towards the center of the enhancer is more severely bent than the outer flanking DN A segments. This information, along with the determination of the helical repeat of supercoiled DNA (11.2 bp/turn) around the hixL-enhancer region (Haykinson and Johnson 1993), allows the structure of the Fis-bound enhancer to be model ed (see Fig. 7). The activation domains of the two Fis dimers are separated by about 120 $\AA$, as measured from the base of the flexible $\beta$-arms, and are rotated $\sim 115^{\circ}$ with respect to each other.

A complex consisting of two hix recombination sites each bound by at least a dimer of Hin must fit within the spatial constraints of the enhancer. M easurements of the diameters of crosslinked paired-hix synaptic complexes by dark-fiel d diffraction electron microscopy are consistent with a tetramer of Hin (S. Ryazantsev, M.J. Haykinson, and R.C. Johnson, unpubl.). Topological studies of the Hin- and Gin-promoted inversion reactions have provided strong evidence that two negative DN A nodes are trapped in the invertasome complex such that the two hix DN A segments are located on opposite sides of the enhancer DNA (Kanaar et al. 1988; Heichman et al. 1991). Of the many possibilities considered, the most plausible configuration of two Hin bound hix sites that fits the spatial arrangement of Fis dimers and the geo- metric arrangement of DNA strands positions the catalytic domains on the outside of the Hin tetramer adjacent to the activating regions of Fis (Fig. 7). Within this model, the hix DNA segments are located in the center of the $\mathrm{Hin}$ tetramer and oriented at $\sim 90^{\circ}$ with respect to each other. This arrangement of the Hin tetramer is similar to one of the models proposed for site I association in the resol vase synaptosome and is consistent with high-resolution electron microscopy of paired-hix complexes (Rice and Steitz 1994a; Yang and Steitz 1995; S. Ryazantsev, M.J. Haykinson, and R.C. Johnson, unpubl.). Whereas the Fis dimers are closer to one of the subunits in each $\mathrm{Hin}$ dimer, one of the Fis $\beta$-arms is directed towards and can easily contact the Hin dimer interface. Thus, this structural model of the invertasome is consistent with the proposed mechanism of Hin activation by Fis. Although this model is compatible with current information on the Hin inversion reaction, the predicted protein interfaces remain to be determined experimentally. We note that the core nucleotides that are exchanged upon recombination are located close to each other such that a relatively modest movement could position the cleaved DNA ends into the recombinant configuration. A mechanism by which multiple DNA exchanges could occur within the complex, leading to the complex knotted DNA products observed from processive recombination, is not apparent (Kanaar et al. 1990; Heichman et al. 1991).

\section{Comparison with the Mu transposon enhancer}

The enhancer elements in both phage Mu transposition and site-specific DNA inversion are believed to be assembled into topologically similar structures and function to increase reaction fidelity, though the precise mechanisms by which the two regulatory elements activate recombination differ somewhat. Like the pairedhix complex by $\mathrm{Hin}$, the $\mathrm{MuA}$ transposase can readily assemble a paired-end complex, which is not active for DNA cleavage (Watson and Chaconas 1996). The Mu enhancer facilitates the assembly of a catalyti cally active MuA transposase tetramer by the formation of transient bivalent interactions between binding sites within the enhancer and the Mu ends (Lavoie and Chaconas 1995). As a functional catalytic unit in the $\mathrm{Mu}$ transpososome is assembled from multiple MuA subunits (Aldaz et al. 1996; Savilahti and Mizuuchi 1996; Yang et al. 1996), a catalytically competent complex is formed in conjunction with enhancer-assisted tetramer assembly. For the resolvase-invertase family, the active site pocket is exclusively contained within one protomer, though amino acids from the partner subunit in the dimer may influence its catal ytic activity (Boocock et al. 1995; Y ang and Steitz 1995). We propose that the hin enhancer, acting via the bound Fis dimers, functions to induce a conformational change in the $\mathrm{Hin}$ dimer to reposition the individual active sites close to the four strands of DNA for a concerted attack. Thus, somewhat different regulatory controls have evolved to lock the $\mathrm{Mu}$ transposase and the Hin DNA invertase in a catalytically inactive state 


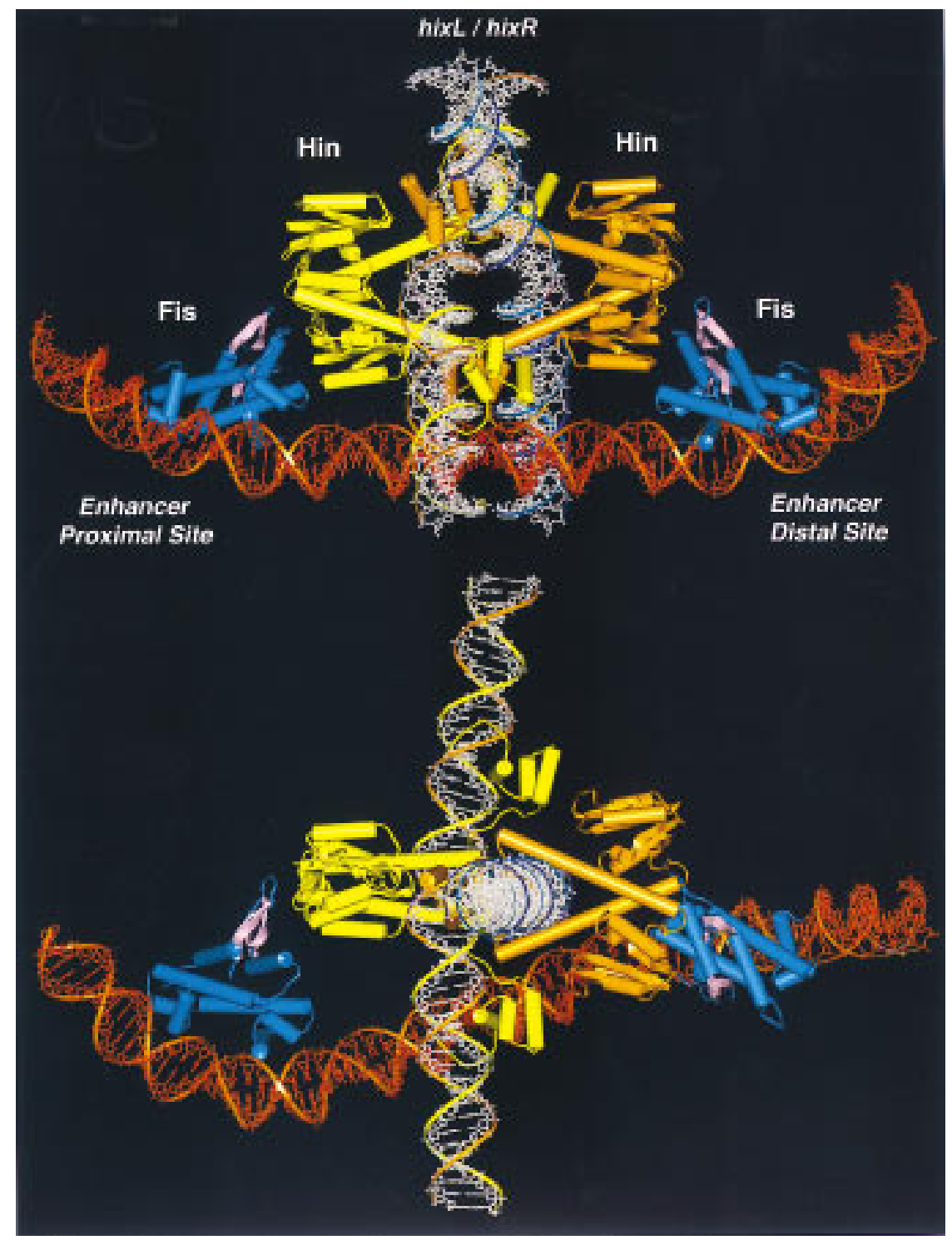

Figure 7. Model of the invertasome complex. Two Fis dimers, depicted in blue with the $\beta$-arm activation domains highlighted in pink, are bound to an enhancer segment of DNA shown in dark orange. Yellow and light orange ribbon diagrams of Hin dimers are complexed with recombination sites on DNA fragments shown in white. (Bottom) The model has been rotated $90^{\circ}$ about the $x$-axis. even in a paired-end or paired-hix complex. The cis-acting enhancer el ements unlock these inhibitory controls and at the same time ensure that only the topologically correct genetic rearrangement occurs. The Hin mutati ons causing Fis independence have released these controls and lead to indiscriminate rearrangements. Deletions that remove a substantial portion of the MuA amino terminus and lead to partial enhancer-independence also release these controls for $\mathrm{Mu}$ transposition (Yang et al. 1995).

\section{Materials and methods}

\section{Fis mutants}

The Fis mutants used in this study were described in Safo et al . (1997) and listed in Table 1. Fis D20K and S30C were combined by standard recombinant DNA methods, and a carboxy-terminal $6 \times \mathrm{His}$ tag was added to D20K/S30C using PCR creating D20K/S30C/His. Fis mutant proteins were purified from cells containing derivatives of pRJ1077, in which fis was expressed from the T 7 promoter as described (Pan et al. 1996).

Fis heterodimers were formed by denaturing and renaturing equival ent amounts of S30C and D20K/S30C/His. The proteins were denatured in $6 \mathrm{~m}$ guanidine chloride, $20 \mathrm{~mm}$ HEPES $(\mathrm{pH}$ 7.5), $0.2 \mathrm{M} \mathrm{N} \mathrm{aCl}, 10 \mathrm{~mm}$ DTT, $20 \%$ glycerol, $1 \mathrm{~mm} \mathrm{CHAPS}$, and $0.1 \mathrm{~mm}$ EDTA at a final protein concentration of $100 \mu \mathrm{g} / \mathrm{ml}$. Equal amounts of the denatured proteins were mixed in a dialysis bag and renatured by dialyzing into the same buffer with decreasing guanidine chloride concentrations over the course of two days. Prior to nickel chromatography, the refolded Fis dimers were dialyzed into $20 \mathrm{~mm}$ sodium phosphate $(\mathrm{pH} 7.4)$, $0.2 \mathrm{M} \mathrm{N} \mathrm{aCl}$, and $20 \%$ glycerol and then incubated with $10 \mathrm{~mm}$ oxidized glutathione at $23^{\circ} \mathrm{C}$ for $3.5 \mathrm{hr}$ to form disulfidelinked dimers. Fis dimers containing at least one $6 \times \mathrm{H}$ is-tagged subunit were purified with the Qiagen Ni-NTA Spin Kit as specified by the manufacturer except that $0.2 \mathrm{M} \mathrm{NaCl}$ was present throughout. The purification was monitored by electrophoresis of the sample on a SDS-polyacrylamide gel in the absence of reducing agent and staining with Coomassie blue. N o S30C homodimer, which lacked the His tag, was detected in the $250 \mathrm{~mm}$ imidazole elution. 


\section{Hin mutants}

The properties of Hin M $101 \mathrm{C}$ were described in Haykinson et al. (1996). The hin mutation H107Y, which was initially isolated as an inversion-proficient suppressor of the inactive F104C mutant (Haykinson et al. 1996), was introduced into an otherwise wild-type hin gene using a two-step PCR-mediated sitedirected mutagenesis protocol (Landt et al. 1990). Hin S10G was generated by a single-step PCR using the corresponding mutant primer that overlapped the unique Clal site in the hin gene ( $M$. Lainé and R.C. Johnson, unpubl.). For purification, the mutant hin genes were cloned into pRJ1518, a derivative of pET 11a (N ovagen) containing the wild-type hin gene under the control of the T 7 promoter. Two liters of Luria broth cultures of RJ1852 [BL21(DE3) fis-767] containing derivatives of pRJ1518 were grown to an $\mathrm{OD}_{600}=0.6$ and induced with $0.1 \mathrm{~mm} \mathrm{IPTG}$ at $10^{\circ} \mathrm{C}$ for $10 \mathrm{hr}$. Cells were lysed and Hin purified essentially as described previously (Haykinson et al. 1996).

$\mathrm{Hin}$ heterodimers were formed by denaturing and mixing the two proteins in the desired ratio in $6 \mathrm{~m}$ guanidine chloride, 20 mM HEPES (pH 7.5), $0.1 \mathrm{~m} \mathrm{~N} \mathrm{aCl}, 10 \mathrm{~mm}$ DTT, 20\% glycerol, 50 mM CHAPS, and $0.1 \mathrm{~mm}$ EDTA at a final protein concentration of $100 \mu \mathrm{g} / \mathrm{ml}$. The denatured proteins were placed in dialysis bags in $100 \mathrm{ml}$ of denaturing buffer and renatured over the course of two days by pumping renaturation buffer (same as above except that no guanidine and $1 \mathrm{~m} \mathrm{~N} \mathrm{aCl}$ was included) into the dialysis buffer while pumping out the dialysis buffer at the same rate $(5 \mathrm{ml} / \mathrm{hr}$ ). After an additional $6 \mathrm{hr}$ dialysis in $100 \%$ renaturing buffer, the proteins were transferred to Hin storage buffer containing $20 \mathrm{~mm}$ HEPES (pH 7.5), $1 \mathrm{~m} \mathrm{NaCl}, 50 \%$ glycerol, $4 \mathrm{~mm}$ CHAPS, and $0.1 \mathrm{~mm}$ EDTA. Purification of heterodimers by a method similar to that used for Fis is not feasible for $\mathrm{Hin}$ because $\mathrm{Hin}$ activity is abolished by amino-terminal tags and reduced significantly by carboxy-terminal tags.

\section{In vitro recombination assays}

The in vitro cleavage and inversion assays were performed and quantitated as described previously in Haykinson et al. (1996) except that reactions employing oxidized mutants were performed in the absence of DTT. The Hin proteins were titrated to determine the minimum amounts required for maximum activity. Unless otherwise noted, these saturating amounts of protein were used in the in vitro reactions. Disulfide-linked preparations of Fis Q21C and S30C as well as Hin M 101C were obtained after long-term storage in buffer containing $\leqslant 1 \mathrm{mM}$ DTT. Oxidized Hin M 101C ${ }^{\circ x}$ in wild-type:M $101 \mathrm{C}$ and M 101C ${ }^{\circ x}$ renatured preparations was generated by incubation with $10 \mathrm{~mm}$ oxidized glutathione for $5 \mathrm{~min}$ in the reaction cocktail prior to initiating the reaction with Fis. Paired-hix complexes formed on pMS634 (Johnson and Simon 1985) were crosslinked with $0.15 \%$ glutaral dehyde for $40 \mathrm{~min}$ at $23^{\circ} \mathrm{C}$. Forty millimolar lysine was added to inactivate remaining cross-linker, and the products were digested with Pstl prior to electrophoresis on a $1 \%$ agarose gel.

\section{Molecular modeling}

M odeling of the invertasome was performed on an SGI Indigo 2 workstation using the Insight II software package (Molecular Simulations). Hin bound to hixL on a 50-bp DN A segment was modeled as described in Haykinson et al. (1996). The K36E Fis structure (Safo et al. 1997) was docked onto the two binding sites within an 83-bp hin enhancer segment such that the overall DNA bending angles at the proximal and distal domains were $65^{\circ}$ and $74^{\circ}$, respectively, and the DNA curvature at each flank conformed with the Fis · 1,10-phenanthroline-copper scission data as described in Pan et al. (1996). The helical repeat of the enhancer DNA was set at $11.2 \mathrm{bp}$, corresponding to twist angles of $-32.14^{\circ}$ (Haykinson and Johnson 1993).

\section{Acknowledgments}

We thank Leah Corselli for isolation and purification of the Fis mutants, Muriel Lainé for isolation and purification of Hin S10G, Hanna Yuan for val uable discussions, and Samson Chow for critical reading of the manuscript. We also thank $Y \mathrm{i}-\mathrm{M}$ eng Yen for help with figure preparation. This work was supported by grant GM 38509 from the $\mathrm{N}$ ational Institutes of Health and by an American Cancer Society Faculty Research Award to R.C.J. S.K.M. was supported in part by U.S. Public Health Service N ational Research Service A ward GM 07185.

The publication costs of this article were defrayed in part by payment of page charges. This article must therefore be hereby marked 'advertisement' in accordance with 18 USC section 1734 solely to indicate this fact.

\section{References}

Adams, C.W., O. Nanassy, R.C. Johnson, and K.T. Hughes. 1997. Role of arginine-43 and arginine-69 of the Hin recombinase catalytic domain in the binding of Hin to the hix DN A recombination sites. Mol. Microbiol. 24: 1235-1247.

Aldaz, H., E. Schuster, and T.A. Baker. 1996. The interwoven architecture of the Mu transposase couples DN A synapsis to catalysis. Cell 85: 257-269.

Boocock, M.R., X. Zhu, and N.D.F. Grindley. 1995. Catalytic residues of gamma delta resolvase act in cis. EMBO J. 14: 5129-5140.

Bruist, M .F., A.C. Glasgow, R.C. Johnson, and M I. Simon. 1987. Fis binding to the recombinational enhancer of the H in DN A inversion system. Genes \& Dev. 1: 762-772.

Crisona, N.J., R. Kanaar, T.N. Gonzalez, E.L. Zechiedrich, A. Klippel, and N.R. Cozzarelli. 1994. Processive recombination by wild-type Gin and an enhancer-independent mutant. Insight into the mechanisms of recombination selectivity and strand exchange. J. Mol. Biol. 243: 437-457.

Feng, J.-A., R.E. Dickerson, and R.C. Johnson. 1994a. Proteins which promote DNA inversion and deletion. Curr. Opin. Struct. Biol. 4: 60-66.

Feng, J.A., R.C. Johnson, and R.E. Dickerson. 1994b. Hin recombinase bound to DNA: The origin of specificity in major and minor groove interactions. Science 263: 348-355.

Glasgow, A.C., M .F. Bruist, and M.I. Simon. 1989a. DN A-binding properties of the Hin recombinase. J. Biol. Chem. 264: 10072-10082.

Glasgow, A.C., K.T. Hughes, and M.I. Simon. 1989b. Bacterial DNA inversion systems. In Mobile DNA (ed. D.E. Berg and M.M. Howe), pp. 637-659. American Society for Microbiology, Washington, D.C.

Haffter, P. and T.A. Bickle. 1988. Enhancer-independent mutants of the $C$ in recombinase have a relaxed topological specificity. EMBO J. 7: 3991-3996.

Haykinson, M.J. and R.C. Johnson. 1993. DN A looping and the helical repeat in vitro and in vivo: Effect of HU protein and enhancer location on Hin invertasome assembly. EMBO J. 12: 2503-2512.

Haykinson, M.J., L.M. Johnson, J. Soong, and R.C. Johnson. 1996. The Hin dimer interface is critical for Fis-mediated activation of the catalytic steps of site-specific DNA inversion. Curr. Biol. 6: 163-177. 
Heichman, K.A. and R.C. Johnson. 1990. The Hin invertasome: Protein-mediated joining of distant recombination sites at the enhancer. Science 249: 511-517.

Heichman, K.A., I.P.G. Moskowitz, and R.C. Johnson. 1991. Configuration of DNA strands and mechanism of strand exchange in the Hin invertasome as revealed by analysis of recombinant knots. Genes \& Dev. 5: 1622-1634.

Hughes, R.E., P.A. Rice, T.A. Steitz, and N.D. Grindley. 1993. Protein-protein interactions directing resolvase site-specific recombination: A structure-function analysis. EMBO J. 12: 1447-1458.

Johnson, R.C. 1991. Mechanism of site-specific DN A inversion in bacteria. Curr. O pin. Genet. Dev. 1: 404-411.

Johnson, R.C. 1995. Site-specific recombinases and their interactions with DN A. In Frontiers in molecular biology: DNAprotein: Structural interactions (ed. D. Lilley), pp. 141-176. IRL Press, Oxford, UK.

Johnson, R.C. and M.I. Simon. 1985. Hin-mediated site-specific recombination requires two 26 bp recombination sites and a 60 bp recombinational enhancer. Cell 41: 781-791.

Johnson, R.C. and M.F. Bruist. 1989. Intermediates in Hin-mediated DNA inversion: A role for Fis and the recombinational enhancer in the strand exchange reaction. EMBO J. 8: 1581-1590.

Johnson, R.C., A.C. Glasgow, and M.I. Simon. 1987. Spatial relationship of the Fis binding sites for $\mathrm{Hin}$ recombinational enhancer activity. Nature 329: 462-465.

Johnson, R.C., C.A. Ball, D. Pfeffer, and M.I. Simon. 1988. Isolation of the gene encoding the Hin recombinational enhancer binding protein. Proc. Natl. Acad. Sci. 85: 34843488.

Kahmann, R., F. Rudt, C. Koch, and G. Mertens. 1985. G inversion in bacteriophage Mu DN A is stimulated by a site within the invertase gene and a host factor. Cell 41: 771-780.

Kanaar, R. and N.R. Cozzarelli. 1992. Roles of supercoiled DN A structure in DNA transactions. Curr. Opin. Struct. Biol. 2: 369-379.

Kanaar, R., A. Klippel, E. Shekhtman, J.M. Dungan, R. Kahmann, and N.R. Cozzarelli. 1990. Processive recombination by the phage Mu Gin system: Implications for the mechanisms of DNA strand exchange, DNA site alignment, and enhancer action. Cell 62: 353-366.

Kanaar, R., P. van de Putte, and N.R. Cozzarelli. 1988. Ginmediated DN A inversion: Product structure and the mechanism of strand exchange. Proc. Natl. Acad. Sci. 85: 752-756.

Klippel, A., K. Cloppenborg, and R. Kahmann. 1988a. Isolation and characterization of unusual Gin mutants. EMBO J. 7: 3983-3989.

Klippel, A., R. Kanaar, R. Kahmann, and N .R. Cozzarelli. 1993. Analysis of strand exchange and DNA binding of enhancerindependent Gin recombinase mutants. EMBO J. 12: 10471057.

Klippel, A., G. Mertens, T. Patschinsky, and R. Kahmann. 1988b. The DNA invertase Gin of phage Mu: Formation of a covalent complex with DNA via a phosphoserine at amino acid position 9. EMBO J. 7: 1229-1237.

Koch, C., J. Vandekerckhove, and R. Kahmann. 1988. Escherichia coli host factor for site-specific DNA inversion: Cloning and characterization of the fis gene. Proc. Natl. Acad. Sci. 85: 4237-4241.

Kostrewa, D., J. Granzin, C. Koch, H.W. Choe, S. Raghunathan, W. Wolf, J. Labahn, R. Kahmann, and W. Saenger. 1991. Three-dimensional structure of the E. coli DN A-binding protein FIS. Nature 349: 178-180.

Landt, O., H.P. Grunert, and U. Hahn. 1990. A general method for rapid site-directed mutagenesis using the polymerase chain reaction. Gene 26: 125-128.

Lavoie, B.D. and G. Chaconas. 1995. Transposition of phage Mu DNA. In Current topics in microbiology and immunology (ed. H. Saedler and A. Gierl), pp. 83-102. Springer-Verlag, N ew York, NY.

Lim, H.M. 1994. Analysis of subunit interaction by introducing disulfide bonds at the dimerization domain of Hin recombinase. J. Biol. Chem. 269: 31134-31142.

Moskowitz, I.P., K.A. Heichman, and R.C. Johnson. 1991. Alignment of recombination sites in Hin-mediated site-specific DN A recombination. Genes \& Dev. 5: 1635-1645.

Pan, C.Q., S.E. Finkel, S.E. Cramton, J.A. Feng, D.S. Sigman, and R.C. Johnson. 1996. Variable structures of Fis-DNA complexes determined by flanking DN A-protein contacts. J. Mol. Biol. 264: 675-695.

Perkins-Balding, D., D.P. Dias, and A.C. Glasgow. 1997. Location, degree, and direction of DNA bending associated with the Hin recombinational enhancer sequence and Fis-enhancer complex. J. Bacteriol. 179: 4747-4753.

Rice, P.A. and T.A. Steitz. 1994a. Model for a DN A-mediated synaptic complex suggested by crystal packing of gamma delta resolvase subunits. EMBO J. 13: 1514-1524.

Rice, P.A. and T.A. Steitz. 1994b. Refinement of gamma delta resolvase reveals a strikingly flexible molecule. Structure 2: 371-384.

Safo, M.K., W.Z. Yang, L. Corselli, S.E. Cramton, H.S. Yuan, and R.C. Johnson. 1997. The transactivation region of the Fis protein that controls site-specific DNA inversion contains extended mobile $\beta$-hairpin arms. EMBO J. 16: 6860-6873.

Savilahti, H. and K. Mizuuchi. 1996. Mu transpositional recombination: Donor DN A cleavage and strand transfer in trans by the Mu transposase. Cell 85: 271-280.

Sherratt, D.J. 1989. Tn3 and rel ated tansposable elements: Sitespecific recombination and transposition. In Mobile DNA (ed. D.E. Berg and M.M. Howe), pp. 163-184. American Society for Microbiology, Washington, D.C.

van de Putte, P. and N. Goosen. 1992. DN A inversions in phages and bacteria. Trends Genet. 8: 457-462.

Watson, M.A. and G. Chaconas. 1996. Three-site synapsis during Mu DNA transposition: A critical intermediate preceding engagement of the active site. Cell 85: 435-445.

Yang, J.Y., M. Jayaram, and R.M. Harshey. 1995. Enhancer-independent variants of phage $\mathrm{Mu}$ transposase: Enhancer-specific stimulation of catalytic activity by a partner transposase. Genes \& Dev. 9: 2545-2555.

Yang, J.Y., M. Jayaram, and R.M. Harshey. 1996. Positional information within the $\mathrm{Mu}$ transposase tetramer: Catalytic contributions of individual monomers. Cell 85: 447-455.

Yang, W. and T.A. Steitz. 1995. Crystal structure of the sitespecific recombinase gamma del ta resolvase compl exed with a 34 bp cleavage site. Cell 82: 193-207.

Yuan, H.S., S.E. Finkel, J.A. Feng, M. Kaczor-Grzeskowiak, R.C. Johnson, and R.E. Dickerson. 1991. The molecular structure of wild-type and a mutant Fis protein: Relationship between mutational changes and recombinational enhancer function or DN A binding. Proc. Natl. Acad. Sci. 88: 9558-9562.

Zhou, Y., S. Busby, and R.H. Ebright. 1993. Identification of the functional subunit of a dimeric transcription activator protein by use of oriented heterodimers. Cell 73: 375-379.

Zhou, Y., P.S. Pendergrast, A. Bell, R. Williams, S. Busby, and R.H. Ebright. 1994. The functional subunit of a dimeric transcription activator protein depends on promoter architecture. EMBO J. 13: 4549-4557. 


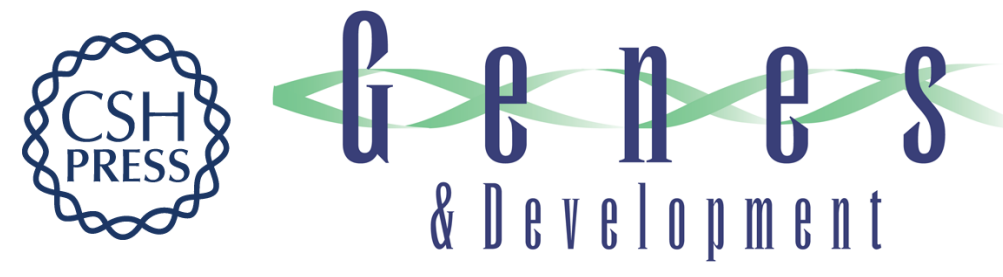

\section{Communication between Hin recombinase and Fis regulatory subunits during coordinate activation of Hin-catalyzed site-specific DNA inversion}

Stacy K. Merickel, Michael J. Haykinson and Reid C. Johnson

Genes Dev. 1998, 12:

Access the most recent version at doi:10.1101/gad.12.17.2803

\section{References This article cites 44 articles, 14 of which can be accessed free at: http://genesdev.cshlp.org/content/12/17/2803.full.html\#ref-list-1}

\section{License}
Email Alerting Service

